\title{
ARQUÉTIPO E REPRESENTAÇÃO NA TELENOVELA: LUGAR COMUM E ESPAÇOS DISCURSIVOS NA REPRESENTAÇÃO DO MESMO NAS PROTAGONISTAS-HELENA DE MANOEL CARLOS
}

\author{
Cristia Rodrigues MIRANDA ${ }^{1}$
}

RESUMO: O presente trabalho visa analisar a constituição de certos arquétipos e estereótipos, na composição das personagens-Helenas de Manoel Carlos , considerando a lógica da indústria cultural e da cultura de massas. Para tanto, serão utilizadas algumas considerações de Morin (1992) sobre a cultura de massas, o conceito de representações sociais, tal como aborda Jodelet (1989), e ainda, abordar-se-ão conceitos sobre a cultura como simulacro Subirats (1998). Consideramos, aqui, que a cultura de massas, como manifestação veemente do imaginário popular e das ideologias, cria representações sociais e, especularmente, tem-se o real produzido e fabricado. Nessa perspectiva, consideramos pertinente analisar as regularidades e as dispersões na composição das personagens- Helena, uma vez que elas se estruturam segundo a lógica da cultura de massas, como também relação à rela reprodução do real em forma de simulacro (re)produzindo e mediando representações sociais.

Palavras-chave: Representação. Personagens. Cultura de massas. Arquétipo. Simulacro

\begin{abstract}
This paper pretends to study some archetypes and models about the compositions in Manoel Carlos's Helenas-character, considering the cultural industry and mass culture. Therefore, will be used some theses about Morin (1992) about mass culture, and the concept about social representations, the same way that Jodelet (1989) addresses the culture idea and the concept the culture like simulation Subirats (1998). Considering that the mass culture, like simulacrum manifestation about the popular imagination and the ideologies creates social representations and specularly the real is built. Hence, we consider appropriate the regularities and dispersions in the compositions of the Helena-character, because they structured as the logic mass culture and the real reproduction in the form of simulation reproducing and mediating social representations.
\end{abstract}

Keywords: Representations. Character. Mass Culture. Archetype. Simalucrum.

\section{Introdução}

Este trabalho tem como objetivo analisar, a partir das teorias da cultura de massa, tal como Morin (1997), Subirats (1989), A cultura como espetáculo dentro das concepções de lugar comum, topoi e representação social, (JODELET, 2001), na construção das personagens protagonistas-Helena de Manoel Carlos. Partir-se-á de algumas concepções teóricas que 
procuram abordar a cultura de massas brasileira e sua manifestação e recepção, dentro do imaginário popular. O objeto é analisar como esta reproduz lugares comuns em espaços discursivos específicos. Para tanto, será necessário considerar a hipótese de que a telenovela, como manifestação veemente da cultura de massas no Brasil, exerce uma influência cultural imprescindível na constituição e reprodução de valores, o que ajudaria a reproduzir mecanismos de identificação e representação.

E, para que se possa pensar em identificação e representação, há de se levar em conta os processos retóricos de reprodução de topoi (lugares comuns) e do pensamento, dentro de um espaço discursivo específico como é a cultura de massas, segundo o que Morin (1969) propõe, bem como a formulação e produção de representação, no âmbito das ideologias. Como objeto de análise dessas construções discursivas, temos as personagens-Helena da ficção dramatúrgica, resultado da obra de ficção do autor de telenovelas brasileiras - Manoel Carlos. Analisaremos tais personagens e seus respectivos comportamentos e papéis sociais, uma vez que se parte do pressuposto de que tais lugares sociais, construídos dentro da ficção dramatúrgica, contribuem para a perpetuação de valores sócio-culturais discursivos. Em Morin (1969, p.36), o imaginário se estrutura segundo arquétipos: figurinos modelos do espírito humano que ordenam os sonhos, racionalizados, míticos ou romanescos. Nesse sentido, consideramos a hipótese de que a ficção teledramatúrgica ajudaria a construir o imaginário popular, nele exercendo uma função angular no que concerne à produção, e circulação de arquétipos, conforme os papéis sociais e relações de classe e representações vigentes.

Este imaginário, se compreendido dentro das concepções discursivas das representações sociais, nos remete à teoria de formulação de topois e de lugares comuns. Ora, as representações sociais, entendidas como fenômenos complexos de trocas sociais de símbolos, contratos, crenças, valores, atitudes, opiniões e imagens, contribuem para a construção de uma ideação coletiva. Se reportarmos às concepções de representação para os estudos da cultura de massa e da indústria cultural, temos, como conclusão, algo parecido com o que Morin (1969 p.29) declara: a indústria cultura persegue a demonstração à sua maneira, padronizando os grandes temas romanescos, fazendo clichês dos arquétipos em estereótipos.

A produção de estereótipos, modelos e figurinos, construídos segundo arquétipos, seguem a lógica da concorrência mercantil, social e econômica. O produto cultural passa a responder mais pelas lógicas do capital e do mercado que pela estética da criação e da arte. Por essa razão, o objeto cultural se transforma mais em produto que em obra de arte, produto esse que é burocratizado pelas leis do mercado e que torna homogeneizado o imaginário, através de topoi perpetuados segundo modelos de pensamento e que se inscrevem através dos arquétipos de mídia. 
A escolha do objeto de análise desse artigo procura demonstrar como a telenovela, como produto veemente da cultura de massa brasileira, contribui para estabelecer e fixar certos topoi, padronizados segundo arquétipos pré-estabelecidos. As personagens-Helena de Manoel Carlos apresentam, em sua composição, algumas características e comportamentos, atitudes que, de certo modo, sincretizam a concepção de mulher-moderna, proposta pela cultura de massas. A fusão dos ideais românticos, o amor platônico que se manifesta na esfera espiritual, e o adultério burguês se fundem para formar uma nova concepção de amor. Esse último que, para se consumar, tem de ser experimentado e representado nestas duas esferas: espiritual, e carnal.

Houve, certamente, uma presença obsessional do amor e no romance cortês, no romance quimérico do século XVII, no teatro burguês do começo do século XX, mas a propriedade da cultura de massa é universalizar, em todos os setores, a obsessão do amor. (MORIN, 1969, p. 72)

Nesse sentido, o tipo de ficção ${ }^{2}$ construída estabeleceria, conforme a nossa hipótese, essa perpetuação da mulher que materializa o amor romântico e o adultério burguês, além de propagar algumas atitudes socialmente estabelecidas, fixando representações. Para viabilizar o estudo, além de serem analisados os comportamentos das personagens-Helena, dentro da ficção dramatúrgica das seguintes telenovelas: Uma história de Amor (1996), Por Amor (2001), Laços de Família (2004), será analisada uma entrevista do autor das referidas novelas ${ }^{3}$, Manoel Carlos, na qual o próprio autor relata sobre suas personagens femininas, especialmente, as personagensHelena, entrevista esta concedida a uma revista de cunho informativo, cujo público alvo é especificamente feminino ${ }^{4}$. Nessa entrevista, o autor depõe sobre a composição de suas personagens, os critérios para elaborar o plot $^{5}$ e os comportamentos pertinentes às atitudes, crenças e valores de suas personagens, especialmente as femininas.

Por fim, confrontaremos as teorias em relação ao objeto proposto, a saber, as personagens-Helena, das obras de ficção teledramatúrgicas supracitadas e as implicações dessas análises na análise do presente objeto de pesquisa.

\section{A CULTURA DE MASSAS}

Segundo a concepção de cultura de massas proposta por Morin (1969), a cultura, o lazer e o entretenimento sofreram várias modificações, devido às mudanças ocasionadas nas relações de troca e à industrialização, como meio de produção e geração de capital, que garantiu mudanças significativas, não somente nas relações de consumo, mas, sobretudo, nas relações de produção.

A partir do século XX, mais precisamente, a partir da década de 30, as relações de produção e criação de produtos, especialmente, os produtos artísticos, sofreram, consideravelmente, as consequências de tais mudanças sociais. A produção artística passa a se orientar pelo consumo e a obra de arte tende a se transformar em produto, organizado segundo o 
modelo da indústria técnica e econômica. Por isso é que, para Morin (1969, p.92) "a burocratização filtra a idéia criadora e o poder cultural se submete ao poder econômico.”.

Dessa forma, alia-se a isso o conceito de indústria cultural, que analisa as manifestações culturais a partir da lógica mercantil.

O conceito de indústria cultural nasce de um texto de Horkheimer e Adorno, publicado em 1947, e o que contextualizou a escritura desse texto é tanto a América do Norte da democracia de massas como a Alemanha nazista. Ali se busca pensar a dialética histórica que, partindo da razão ilustrada, desemboca na irracionalidade que articula totalitarismo político e massificação cultural como as duas faces de uma mesma dinâmica (BARBERO 1997, p.65).

Este conceito (oriundo da escola de Frankfurt) ajuda a explicar o lugar da cultura, a partir do advento e da permanência do capitalismo e da totalização dos movimentos nazistas. Para esses, os frankfurtianos, a indústria cultural seria um instrumento para dominação da coletividade. Há de se considerar, ainda, que, no âmbito dos estudos da cultura, como processo industrial e contendo o logos mercantil, os estudos de Benjamim contribuem com uma espécie de crítica capaz de pensar o não-pensado, (BARBERO, 1997 p.57). A cultura marginal e popular não para sua negação, mas a partir de suas próprias condições, a saber, a experiência e a produção cultural.

O estranhamento da arte, dentro do conceito de indústria cultural, leva à saturação e também à dialética entre cultura e massas. Por isso é que para os frankfurtianos, especialmente Horkheimer e Adorno, o termo caos cultural é usado para se referir à produção da cultura de massas. A lógica da produção reside na industrialização da cultura, através da racionalização dos meios técnicos e da produção em si. Embora a análise frankfurtiana dos movimentos culturais modernos seja considerada de um pessimismo ceticismo capazes de negar tais movimentos culturais, pode-se considerar tal análise satisfatoriamente eficaz, quando se pensa em movimento cultural e lógica do mercado. Muito embora, pensar nestes movimentos, para depois negar a sua legitimidade, só por fazer parte de um movimento popular em si, o que para Barbero (1997, p.87), cheira a um aristocracismo cultural. Assim, para os frankfurtianos, a arte se incorpora ao mercado, como bem cultural e adapta-se à necessidade - identificação com a fórmula e a repetição da mesma.

Mas, em Benjamim, a experiência e a técnica servem como mediadores da cultura e à medida que as novas aspirações das massas avançam e se modificam, mais há identificação entre as massas e a representação, nesta esfera discursiva que é a cultura de massas. Desta forma, a produção e a recepção passam a se coordenarem, perpetuando as relações entre o espaço imaginativo e o espaço da recepção sofrendo, juntos, interferências que são as interfaces dessa dialética social e cultural.

Por isso é que o espaço fictício e subjetivo reclama para si mais doses de realismo; e esse sincretismo entre ficção e informação norteia as produções que, por sua vez, já vêm 
previamente determinadas pela recepção. Recepção esta que requer um lugar imaginativo que libere os seus desejos reprimidos pela aspereza do cotidiano e que, ao mesmo tempo, passa a se reportar a este lugar seguro e confortavelmente tangível que é o real. Desta forma, o real e o imaginário se fundem numa espécie de representação, que é para Morin (1969) mecanismo fundamental para a alienação.

Morin (1969) pensa a indústria cultural como o conjunto de intercâmbio cotidiano entre o real e o imaginário. Tal abordagem demonstra a relação entre sua teoria e a de Freud (???) (mecanismo de identificação-projeção), em que, pressupostamente, existe uma predisposição e uma inclinação da psique, de todo sujeito, em se identificar-projetar, através de mitos e de heróis. Nesse sentido, a cultura de massas transforma muito bem tais mitos e heróis em arquétipos e modelos para as massas. Mas, ao mesmo tempo, são também, uma espécie de herança cultural, que advêm da figura cristalizada do mito, concomitantemente à sua adaptação ao consumo, à produção e ao mercado.

Então, reproduzem-se os mitos na cultura de massa, segundo as lógicas que a própria cultura requer:

Se uma mitologia funciona é porque dá resposta a interrogações e vazios não preenchidos, a uma demanda coletiva latente, por meios e esperanças que nem o racionalismo na ordem dos saberes nem o progresso na ordem dos haveres têm conseguido extirpar ou satisfazer. (BARBERO, 1997 p.83)

Tratado dessa forma, a cultura de massa institui uma nova combinação: a produção e a criação, e seguem à risca o modelo burocrático-industrial, tais como: homogeneização do produto que se torna universal, racionalização da produção, de tal forma que o produto para se projetar-identificar com as grandes massas de consumidores - receptores tem que ser um produto comum, universal que medeie as relações entre cultura e massa.

O imaginário trabalha e se estrutura segundo arquétipos, e, por isso, fabrica-se o desejo, a partir de certos modelos tornados conscientes e racionalizados. Por isso é que a criação cultural não pode ser totalmente integrada num sistema de produção industrial Morin (1969). O que existe, então, é um desequilíbrio entre as forças contrárias: burocráticas e antiburocráticas. Nesse cenário ideológico, a cultura de massa traça suas diretrizes, em um constante transitar dos discursos da tradição e modernidade, dos conceitos de ruptura, e contemporaneidade em que o padrão se beneficia do passado e o original é a garantia do novo sucesso. (MORIN, 1969 p. 31).

A criação arquetípica da cultura industrializada tende a cada vez mais se tornar em produção como antes declarado. Em certo sentido, a produção tende a consagrar o produto como mediador entre o velho e o novo: é surpreendente a analogia entre os heróis homéricos ou os cavaleiros da Távola Redonda, cantados por vagas sucessivas de poetas esquecidos, e os heróis das revistas em quadrinhos da imprensa de massa (MORIN, 1969, p.32). 
Os grandes temas do imaginário são, eles mesmos, em certo sentido, arquétipos e estereótipos. O padrão torna-se a forma, e a produção, que é sempre ligada ao consumo, se destina a um público diversificado, ao mesmo tempo, que tende a homogeneizar este público através da repetição, da representação do mesmo, do sincretismo e do apelo à padronização dos temas, neste diálogo entre realidade e ficção.

As produções culturais, a partir da década de 30, parecem valorizar tudo o que na ficção se torne cada vez mais verossímil, ou que corresponda a esta proximidade com o real, no setor do romanesco: no setor imaginário o realismo domina as ações e intrigas romanescas que têm as aparências da realidade. De acordo com Morin (1969), a cultura de massa é animada por esse duplo movimento do imaginário remendando o real, pegando as cores do imaginário.

\section{O ESPETÁCULO NA CULTURA: a cultura como simulacro}

Para considerar a cultura de massas, neste âmbito da representação, há de se considerar que a própria cultura de massas pode ser reconhecida como manifestação artística. Em Subirats (1989), a arte é em si mesma a representação do real e empresta seu valor estético ao mesmo real. As concepções que Subirats (1989) traça sobre simulacro são, também, apontamentos que podem ser entendidos como conceitos sobre representação, quando define o simulacro como a réplica de algo, do ser verdadeiro:

O simulacro é a duplicação formal dessa experiência como produto acabado,
portanto como algo que podemos assumir ou refletir, mas nunca se nos revela
como experiência subjetiva. É uma simulação de sua mais perfeita fidelidade
às qualidades lógicas ou sensíveis da reprodução que implica em sua
pretensão ilusionística e suplantar ou superar a experiência do real, um
princípio de ocultação e opacidade (SUBIRATS, 1989, p.62).

Por isso que em Subirats (1989), o conceito de simulacro, como réplica teatral, sombras ou imagens especulares, pode ser ampliado para um conceito técnico-científico, no qual o simulacro empresta à cultura algumas definições programáticas, ao mesmo tempo em que define a experiência. Nesse sentido, a cultura, enquanto simulacro, pode ser comparada à produção de conhecimento científico e à capacidade do homem de criar. Para Subirats (1989, p. 36) arte, produção técnica e conhecimento científico das leis do universo se subordinavam a um mesmo princípio objetivo de beleza.

Não existe uma barreira definida entre o empírico, e, portanto, materialmente verificável, entre a técnica e a obra de arte. A arte passa a se vincular à técnica. Dessa forma, surgem as contradições com a vinculação entre cultura e tecnologia, porque a cultura tecnológica une a forma e a cultura. Com efeito, tem-se a degradação do novo conceito de cultura: ligado aos aspectos racionais e burocratizados.

A produção como simulacro se orienta pela perspectiva racional e colonizada de todos os aspectos da vida humana. Esse conceito de cultura, como simulacro, possui poderes 
mitológicos e ontológicos de fazer constituir a realidade que não é outra senão aquela produzida através deste simulacro cultural. O simulacro, neste conceito de cultura tecnológica, veicula o ato de representação do real, e nada mais apropriado para a concepção de representação do que a de que a própria cultura se nutre de imagens especulares do mundo. A racionalidade instrumental de todos os aspectos da vida humana ajuda a tornar a cultura em simulacro, no sentido de que esta possui mecanismos capazes de gerar ideologicamente a realidade fabricada. O espetáculo das imagens, ao mesmo tempo em que se nutre da realidade, a substitui com representações. A cultura, enquanto espetáculo serve-se das imagens que, por sua vez, criam representações.

A relação entre a concepção de simulacro, proposta por Subirats (1989), e a indústria da cultura e do espetáculo faz com que essa dialética da imagem, com o real e, por sua vez, com a representação, possa ser analisada a partir do âmbito das ideologias, da construção da ordem consensual, através da hierarquização dos valores, que só é possível através da perpetuação de mitos e de ídolos e da instauração de estereótipos:

$$
\begin{aligned}
& \text { os ídolos, do mesmo modo que as ideologias, não são cópias imprecisas das } \\
& \text { representações verdadeiras do ser. São, antes, as representações das coisas } \\
& \text { enquanto arrebatadas à suas experiências e dotadas de uma qualidade } \\
& \text { ontológica (SUBIRATS, 1989, p.63). }
\end{aligned}
$$

Mas, com o advento das técnicas para a fabricação do simulacro e com o objetivo de se produzir uma realidade para tal sociedade do consumo, a cultura de massas perde uma identidade cultural estável e passa a se orientar segundo a racionalização dos meios e mediações de produção. Isso, entre outras coisas, doravante propiciará críticas que apontam para um empobrecimento estético do fazer cultural e do fazer artístico.

Portanto, o simulacro se coloca diante das condições de pressuposição idealista do mundo e, por isso, o simulacro é a fabricação do real. Em Subirats $(1989$, p. 64) "temos que o simulacro é a representação, a réplica científico-técnica, linguística e multimidial do real, convertida em segunda natureza, em mundo, no real em sentido absoluto."

A representação do real, no entanto, como aponta Subirats (1989), se dá em vários âmbitos e se transforma na condição ontológica do ser social: a condição de se transformar em imagem. Outra consequência, que advém da cultura como simulacro, é que a identidade comunitária e coletiva passa a ser determinada pelo real fabricado, virtual e fictício, constituindo relações entre o ser e sua imagem de forma simbólica e ideológica. A partir destas concepções desenvolvidas por Subirats (1989) essa teoria que concebe a cultura de massas como simulacro abre um campo propício para se analisar os meios e as mediações dentro deste universo da modernidade.

A mídia, como espaço convergente e homogeneizante da coletividade, especialmente a televisão, se transforma em uma espécie de olho do universo, oráculo da realidade. A televisão 
passa a ser a janela que oculta e, ao mesmo tempo, abre as possibilidades para o real-fabricado. Sob a égide da mediação, ela é o mundo das sombras descrito em o Mito da Caverna ${ }^{6}$, cujos prisioneiros constroem sua realidade através do universo que as sombras projetavam. É o universo imagético que reclama posição favorável na constituição do ser, enquanto sujeito submetido aos lugares representacionais.

A comunicação midiática televisiva projeta as imagens para o coletivo, ao mesmo tempo em que este mesmo coletivo espera por seu alter-ego ${ }^{7}$ fabricado nas telas. Em contrapartida, as imagens fabricadas pela cultura de massas liberam o id subjetivo ${ }^{8}$ do indivíduo para que ele possa, através de projeção-identificação, dar escape aos seus desejos, através de experiências virtuais, nunca reais. Esta inversão dos valores reais e imaginários, o lugar sagrado ocupado pela imagem na pós-modernidade, só é possível porque os meios técnicos permitem uma alienada perda de autonomia por parte do homem moderno. Dessa forma, os meios técnicos irão colonizar a vida, racionalizando a cultura transformando-se em mediação do indivíduo para com suas representações criadas pelas forças endocêntricas que a sustentam.

Assim produz-se um novo sistema, um novo método de instrução das massas, com novas técnicas de ideação, mas, sobretudo, novos métodos e mecanismo de representação e identificação das massas. Esses procedimentos se dão a partir da racionalização e da homogeneização desse homem médio. Há sempre uma oposição sincrética entre o coletivismo e o individualismo, produzido na cultura como simulacro: produz-se uma identidade, ao mesmo tempo, subjetiva e social e por outro lado, também, individual. Com efeito, as imagens são compartilhadas e a experiência que elas proporcionam levam à identificação com o simulacro midiático.

\section{A TEORIA DA REPRESENTAÇÃO E A CULTURA DE MASSAS}

O estudo das representações, especialmente no âmbito dos estudos da cultura, tem uma relativa importância, se considerarmos a relevância que a cultura de massas e o simulacro midiático produzem no fenômeno chamado de projeção - identificação ${ }^{9}$. Muitas são as definições e os campos de saberes que abordam os fenômenos das representações.

Para Jodelet (2001, p.32) "representar ou se representar corresponde a um ato de pensamento pelo qual um sujeito se reporta a um objeto (...) não há representação sem objeto." Dessa forma, o domínio das representações, a partir de concepções sócio-discursivas e psicanalíticas, concebem as representações como fenômenos complexos sempre ativados e em ação na vida social.

A relação entre sujeito e objeto de que fala Jodelet (2001), que se reporta a atos de pensamento pelo qual um sujeito se relaciona com um objeto, não se dá de maneira simples. As 
representações, enquanto materialização imagética do pensamento dá-se de forma simbólica e também de forma sígnica.

Contudo, devemos conceber tais objetos, nas representações, como Jodelet (2001, p.24) o concebe: "os objetos são produções mentais sociais". O estudo das ideologias, portanto, vem conceber essa relação entre objeto, produção mental e sociedade. Nos trabalhos de Bakhtin (1995) pode-se verificar um esforço para explicar esta relação entre as produções mentais, os objetos transformados em signo pela coletividade e, consequentemente, a produção de uma ideologia. Para analisar os estudos da ideologia, e vinculá-los aos estudos da linguagem, Bakhtin (1995) relaciona o signo e a produção de signo às ideologias, uma vez que, tudo que é ideológico possui um significado. $\mathrm{O}$ autor conclui, então, que sem signos não existe ideologia:

No entanto, todo corpo físico pode ser percebido como símbolo: é o caso, por exemplo, da simbolização do princípio da inércia e de necessidade na natureza (determinismo) por um determinado objeto. E toda imagem artístico-simbólica ocasionada por um objeto físico particular já é um produto ideológico. Converte-se assim em signo o objeto físico, o qual, sem deixar de fazer parte da realidade material, passa a refletir e a refratar numa certa medida, uma outra realidade. (BAKHTIN, 1995, p.31)

No entanto, a relação entre objeto, signo e ideologia só se torna socialmente compartilhada acaso se pense em representações, enquanto produções cognitivas, informativas, ideológicas, normativas, mentais, sociais e consensuais. Essa relação só se dá a partir de forças harmônicas criadas dentro de um sistema de crença que produz e reproduz de forma cíclica os valores reconhecidos e projetados. A partir daí, o signo e o objeto se colocam, em relação ao sujeito, como mecanismos e dispositivos capazes de formar um sistema de representação para que o mundo esteja em constante interpretação.

Enquanto sistema de interpretação que rege nossa relação com o mundo e com os outros, as representações, servindo como subsídio para ideologia, organizam as condutas e as comunicações sociais. Assim, a representação mental bem como a representação pictórica e a representação na cultura como simulacro, apresenta o objeto substituindo - o por um símbolo, ou por um signo, capaz de dar conta de todo o universo ideológico determinado pela coletividade.

As representações sociais, articuladas ao estudo das ideologias, consideram a sua vocação comunicacional. Ora, se as relações sociais afetam as representações, bem como a realidade material, ideacional, social sobre a qual elas têm de intervir, há de se considerar que, a comunicação midiática cria um espaço propício para que tais representações possam se colocar à disposição do indivíduo /sujeito.

Para Jodelet (2001), a representação social mantém com o seu objeto uma relação simbólica (substituindo-o) e de interpretação (significação); E ainda: 
Não se pode eliminar da noção de representação social as referências aos múltiplos processos individuais, interindividuais, intergrupais e ideológicos que freqüentemente reagem mutuamente uns aos outros e cujas dinâmicas de conjunto resultam nessas realidades vivas que são as representações sociais. (DOISE 2008 apud JODELET 2001 p.26)

Acrescente-se a estas referências individuais, interindividuais, intergrupais e ideológicas o papel da comunicação relacionado às representações. A comunicação social e seus diferentes canais concorrem para a criação de um universo consensual, que acaba sendo propício ao estabelecimento de representações e processos de identificação. Dessa forma, a comunicação, especialmente a comunicação midiática, contribui para a formação e a edificação de elementos propícios às representações sociais, concernentes à conduta: opinião, atitude, estereótipo, valores. Em se tratando de comunicação midiática, pode-se perceber que a mesma teria uma preocupação latente em difundir e formar opiniões, estabelecer regras de pensamento, perpetuando os topois, como lugares privilegiados, em que o pensamento, o real, e a produção cultural coincidem:

A incidência da comunicação é examinada por Moscovici em três níveis: (...)
Ao nível das dimensões das representações relacionadas à edificação da
conduta: opinião, atitude e estereótipo, sobre os quais intervêm os sistemas
de comunicação midiáticos. Estes, segundo pesquisas dos efeitos sobre sua
audiência têm propriedades estruturais diferentes, correspondentes à difusão,
à propagação e à propaganda. A difusão é relacionada com a formação das
opiniões; a propagação com a formação de atitudes e a propaganda com a dos
estereótipos.(DOISE- apud, JODELET,2001, p.26.30)

A comunicação midiática participa dos processos de produção, propagação e difusão, representação do real, quando estrutura o pensamento de acordo com modelos préestabelecidos, quer seja pela necessidade de mercado quer seja pelas ideologias dominantes. Por isso, as representações são também culturais, heranças do pensamento secular e, ao mesmo tempo, produções arquetípicas da sociedade pós-moderna, particularmente, dentro do universo midiático. Ora, de todas as atividades humanas, a fabricação de fatos, de pensamentos, a transformação de objetos em símbolo e de realidade em signo são as mais culturais, e são as que se referem a processos de representação, a partir das ideologias coletivas.

A representação seria algo que considera um posicionamento sócio-discursivo, ideológico e, por isso, sempre manterá com a realidade uma relação de projeção - identificação; já que a representação partirá sempre do princípio de que a identidade e a diferença são dois pólos que pertencem ao sistema projetivo. Em Hall (1998, p.55), as identidades são construídas dentro do discurso e sempre se reportarão a lugares histórico - sociais específico.

Portanto, os dispositivos das representações são as ideologias, a linguagem, os discursos, sendo que os constituintes da representação são as informações, as imagens, as crenças, os valores, as opiniões, os elementos culturais e ideológicos, em constante relação, uns com os outros. Relacionar a teoria das representações com os estudos da Cultura de Massa, a 
partir dos conceitos de Indústria Cultural desenvolvidos por Barbero (1997) e por Morin (1969) se torna necessário, uma vez que se considera que a indústria cultural sempre procurará a repetição, quer seja em nome da padronização da cultura e a produção de um certo tipo de homem médio, quer seja em nome da perpetuação de um universo consensual. Por isso a produção de técnicas padrão e a constituição de elementos arquetípicos, e ou lugares comuns, se transformam em receita para a produção de cultura na Indústria da cultura de massas.

\section{A INDÚSTRIA CULTURAL BRASILEIRA: as telenovelas como cultura de massa}

A indústria cultural brasileira segue, em certo sentido, os mesmos moldes da indústria cultural descrita por Morin, e que se desenvolvera a partir da década de 30. A televisão que coincide com a implantação dos movimentos totalitários (nazismo, fascismo), passa a exercer a função de controle, de veicular ideologias e a propor um universo consensual.

Nesse contexto, a cultura de massas tem um papel imprescindível para homogeneização do pensamento. A televisão, como meio de comunicação, até então, mais rápido eficaz e universal, passa a ser o veículo pelo qual os líderes têm acesso às suas grandes massas. A partir da década de 50, a sociedade brasileira também conhece a eficácia da televisão que se consolida aos poucos e passa a incorporar o maior número de poderes possível: o poder de informar, de entreter, de ensinar e, principalmente, o poder de formar opiniões.

A cultura de massas parece se preocupar em formular temas que reúnam condições de estabelecer o que Morin (1969) denomina o homem médio. Com isso, elementos da ficção e da informação são ambos imprescindíveis para a fórmula e para a repetição do mesmo. Neste contexto, as telenovelas brasileiras procuram adaptar as condições às necessidades de fabricação do desejo, da realidade e, principalmente, na produção de grandes temas que reproduzam valores universais. Produzidas segundo a lógica da indústria cultural, racionalizando a produção, burocratizando as técnicas, a telenovela passa a incorporar a mais eficiente produção cultural para as massas. Acrescente-se a isto, que o significado econômico da telenovela passa a ser também analisado a partir dos estudos da cultura de massa.

É inconcebível entendermos o fenômeno da telenovela sem levarmos em consideração o seu significado econômico. A própria natureza da televisão comercial, baseada na exibição de uma programação contínua de horas/ texto já nos coloca diante do problema da rentabilidade dos produtos. (ORTIZ, 1989, p.112)

A tele-novela torna-se um produto rentável e extremamente barato se comparada a outros tipos de dramaturgias, nacionais ou estrangeiras. O mercado brasileiro passa a incorporar e a consumir este produto com uma intensidade cada vez mais voraz. A partir da década de 70, a tele-novela, especialmente aquelas produzidas pela Rede Globo de televisão, expande o seu raio 
de atuação e passa a exportar o seu produto para outros países transformando a telenovela um produto padronizado universalmente.

Assim, o referido produto compõe, nacionalmente, a discussão moderna sobre os produtos culturais, fortemente influenciadas pelas concepções de produto da Indústria Cultural da Escola de Frankfurt. A telenovela também é caracterizada, a partir desses conceitos, como um tipo de produção que não incorpora as especificidades de uma produção artístico-cultural. Neste tipo de análise, consideram-se as telenovelas como um tipo de mercadoria, uma espécie de produto de troca, sem nenhuma especificidade, uma vez que não são feitas para serem lembradas. Em Ortiz (1989, p. 121), "trata-se realmente de produtos que possuem uma obsolência muito mais rápida do que um cd, ou um filme, que podem ser sempre escutados ou vistos, em momentos posteriores ao seu lançamento no mercado".

Mas a discussão, no âmbito cultural, permanece sobre a produção e a padronização do produto telenovela e seus atributos artísticos. Mas, ainda sim, considera-se que a produção das telenovelas, seguindo a lógica da indústria cultural, arrisca pouco, e o modelo produzido, segundo formas pré-determinadas, tende a se repetir, orientando-se pelo processo da recepção, se a fórmula tiver sucesso.

Como processo de produção industrial, o produto telenovelas tem se modificado, no decorrer dos anos, principalmente, se considerarmos que as tele-novelas são produzidas a partir do evoluir das técnicas que dão subsídio à sua produção. No que concerne à produção de sonoplastia, equipamentos técnicos, informatização, e a preocupação em se contratar pessoas especializadas para cuidarem dos assuntos que envolviam técnicas, as telenovelas modificaram consideravelmente o seu formato.

Os grandes temas universais vêm preenchendo o formato narrativo das telenovelas, e assim, a fórmula de sucesso é a repetição do mesmo. O amor, como tema universal, sofre alterações para se adaptar às novas exigências da sociedade pós-moderna. A partir dos anos 30 , como acentua Morin (1969, p. 138) "o amor transpõe a barreira sexual para realizar-se numa união dos corpos: supera o obstáculo da vida." Neste âmbito, o romance burguês e a novela de cavalaria emprestariam a este novo formato narrativo o seu grande tema: o amor. Sendo que, nesse tipo de produção ficcional, pós-moderno, o amor tem embalagem nova, com a conjugação do amor carnal e do amor espiritual. A sensualidade contida no beijo projeta um novo tipo de erotização que vem ligada ao rosto.

Dessa forma, a produção típica da cultura de massas do século XX, no nosso caso, a telenovela brasileira, consegue sincretizar, com grande êxito a fusão entre o Eros e a psiqué. Morin (1969 p.140) aponta que:

o beijo na boca não é só o substituto cinematográfico da união dos corpos proibida pelos censores é também o encontro de Eros e Psyché: (...) o beijo 
na boca é um ato de duplo consumo antropofágico de absorção da substância carnal e de troca de almas; e comunhão e comunicação da psique no eros.

Nessa lógica, a indústria da telenovela brasileira procura seguir estas formas, tão exploradas na indústria cinematográfica e que agora passam a integrar os elementos básicos no formato narrativo, da mais importante e rentável parcela da indústria cultural brasileira, a teledramaturgia: dualidade entre sexo e amor, extinção dos recalques a partir do constante apelo ao hedonismo, incesto, são temas sempre explorados.

Essa busca em parte don-juanesca, em parte tristanesca que procura efetuar a conjugação de Eros e Psique, faz aparecer o movimento complexo e profundo do individualismo moderno (...) ser reconhecido e reconhecer, perder-se e afirmar-se no olhar de um alter-ego amoroso e achar em escala proporcional ao casal valores do incesto, da família, da religião, da conquista e da escravidão, da vida privada do mundo burocrático, o que efetivamente, na linguagem burguesa se chama "aventura" (MORIN, 1969, p. 144).

A dramaturgia brasileira converteu, com grande sucesso, esta tendência da cultura de massas em criar temas universais, e repetir a fórmula de sucesso. Mesmo porque a criação de personagens "universais" e temas, também universais, constituem uma técnica de composição de narrativa que há muito vem dando certo.

Os incestos, triângulos amorosos, e a grande convergência do amor profano em amor sagrado, bem como a constituição de um novo tipo de estereótipo feminino: a virgem e a vamp (MORIN, 1992, p.57) faz com que a experiência dramatúrgica passe a veicular comportamentos e valores para a sociedade, num processo especular de tamanha importância que não se sabe mais precisar onde nascem os lugares comuns, as representações e os arquétipos, e onde eles são perpetuados: dentro ou fora das telas.

\section{AS PERSONAGENS-HELENA DE MANOEL CARLOS: arquétipo e representação}

Um processo de composição de personagens e de criação dos mesmos evidencia, ainda que involuntariamente, os procedimentos teóricos acima descritos: a saber, a indústria cultural, a cultura como simulacro, as representações sociais; todas estas considerações, acerca da cultura de massa, podem ser observadas na produção cultural da telenovela, mais especificamente, e no caso da análise proposta, na composição de personagens, no que diz respeito à construção do padrão, dos arquétipos de que fala Morin (1992).

No caso das personagens protagonistas de Manoel Carlos, pressupostamente há uma fórmula para ser repetida nas três novelas analisadas. A primeira novela, Por Amor, exibida às 18 horas no ano de 1996, apresenta, como personagem principal, uma mulher, de nome Helena, pertencente à classe média . Mãe de uma única filha, separada do marido, com o qual estabelece uma relação de amizade que se estende também à mulher do ex-marido. Possui uma única filhaJoyce- por quem nutre uma dedicação e um amor incontestes. A primeira cena da novela é uma 
briga no trânsito, entre Joyce e seu namorado - Caio. Briga assistida pelo médico - Carlos, que, coincidentemente, estaria a caminho do altar. Joyce estaria ferida e grávida do namorado. Carlos ao ver a moça jogada ao chão, e não assistida pelo mesmo, resolve socorrê-la. Tira-a rapidamente do chão e a leva para o Hospital, interrompendo de forma trágica e espetacular o seu próprio casamento com a personagem Paula.

A partir daí a sua mãe, Helena, é acionada e a trama começa a se desenvolver entre os personagens-Helena, Carlos, Paula-, que é o primeiro triângulo amoroso, e entre - Helena, Caio e Joyce - relação entre mãe e filha e o antagonista. Em tal novela, a protagonista Helena pode ser considerada um modelo de mulher média ${ }^{10}$ da sociedade brasileira. Separada, mãe de uma filha, corretora de imóveis e pertencente à classe média urbana carioca e que se envolve apenas em relacionamentos duradouros, honestos e sóbrios.

Os conflitos dessa personagem advêm não de sua condição econômica e social, mas de seus problemas relacionados aos papéis sociais e subjetivos que exerce: mãe, amante, exmulher, amiga, .profissional Sempre disposta a ajudar a compreender, e principalmente, a atrair para si a sua condição de mãe e de mulher, de forma intensa e pungente. Perfilamos que, nas seguidas novelas do autor, Manoel Carlos, tal forma irá se repetir em suas demais protagonistas: a repetição do nome Helena e sua condição de protagonista pode não ser feita de forma tão aleatória.

Na próxima telenovela analisada, Por amor (1997), a personagem principal interpretada pela mesma atriz (Regina Duarte), também tem o nome Helena; possui as mesmas características da primeira, embora o fio narrativo se modifique um pouco. Mulher, mãe de filha única, separada, profissional autônoma (sócia-proprietária de um escritório de decoração), portanto, também pertencente à classe média. Sua condição de amante não se sobrepõe à sua condição de mãe, condição essencial ao fluxo narrativo da trama. Sua filha, Eduarda, (intencionalmente, ou não, interpretada pela filha da atriz, Gabriela Duarte) é uma personagem que reúne características arquetípicas de uma filha única, e criada sem a presença paterna: frágil, mimada, indefesa, insegura e romântica. A mãe, por sua vez, reúne arquétipos de mãe, de filha única: classe média, que por sua vez, coloca, acima de tudo, a maternidade como condição primordial à sua existência.

A identidade fragmentada de que fala Hall (1998) pode ser verificada na construção discursiva dessas personagens-protagonistas: tanto em Por Amor quanto em Uma História de Amor, em que constantemente suas condições de amante e de mulher são colocadas em tensão, o chega a uma saturação na segunda novela, em que filha e mãe engravidam simultaneamente e, coincidentemente, dão à luz no mesmo dia. Helena, ao saber que o neto (filho de Eduarda) havia morrido, e que a filha não poderia- depois do parto traumático- gerar outras vidas novamente, com a ajuda de um amigo da família, troca o seu filho vivo pelo filho morto de Eduarda. 
Os conflitos que se sucedem em ambas as novelas e, posteriormente, na próxima novela de Manoel Carlos, atenuarão essas condições conflitantes entre a mulher, amante e mãe, através dos conflitos vividos pelas personagens-Helena. Em Laços de Família, a personagemprotagonista, para manter o arquétipo, o mesmo perfil social que as outras Helenas: mãe, profissional autônoma (proprietária de uma clínica de estética), apesar de esta personagem ser mãe de dois filhos, possui a condição de mãe solteira, pertencente a classe média urbana carioca.

Nessa protagonista vê-se a consubstanciação de que fala Morin (1969) entre o sagrado e o profano, entre a virgem e a Vamp: Helena, uma personagem que beira aos 50 anos, mas que desperta fascínio entre os homens pela sua beleza evidente, apaixona-se por um rapaz com a idade de seus filhos. As cenas entre o casal, Helena e seu amante Edu, são adornadas por beijos cuja sensualidade explora a consubstanciação entre Eros e psique, de que fala Morin. Abdicar-se de um amor, em nome da filha, Camila, que se encontra apaixonada pelo seu namorado - Edu, é o gesto que une as duas pontas entre o sagrado e o profano.

A personagem, ainda, posteriormente, com a doença da filha, se dispõe a se deitar, novamente, com o pai de Camila, Pedro, seu primo, que até nesse momento da trama não sabia de sua condição paterna. Engravidar novamente era a possibilidade de oferecer a cura à filha, leucêmica, e que, portanto, precisava do transplante de uma medula compatível para continuar vivendo. Tem-se, mais uma vez, a conjugação entre o sagrado e o profano.

Nestas três personagens, no entanto, vê-se um encadeamento narrativo que leva a construção de um padrão de personagem que em um processo especular de refração e produção de arquétipos, já descrito acima, acaba por reproduzir projeção e identificação no processo da recepção: esse tipo de padrão moderno e universal faz com que a projeção-identificação seja também, de representação, na esfera discursiva da comunicação e da ficção. Dessa forma, através da cultura de massa, nesse caso, através das telenovelas, perpetuam-se certos pensamentos, topois e lugares comuns, permitindo que o processo de representação seja criado a partir do simulacro midiático: mulher moderna, amor incondicional de mãe, amante, profissional autônoma, poderiam ser definidos como arquétipos e representação, em uma determinada época, para papéis sociais, tipicamente femininos. Nesse sentido, a arte enquanto recriação do real vai de encontro aos anseios de perpetuação dos dizeres, das atitudes e dos comportamentos.

A produção deste novo arquetípico de homem médio (MORIN, 1992), na sociedade pósmoderna tem que mediar os valores da tradição e também os valores da modernidade: a construção das personagens Helena parece levar em conta os valores sociais modernos: a condição de mulher independente de profissional autônoma, capaz de criar os filhos sem a presença da figura masculina, ao passo em que também escolhe com quem se relacionar sem 
depender psicológica e financeiramente da figura masculina. Não obstante, essa condição arquetípica e pós-moderna também alia $\mathrm{E}$ os valores e atitudes tradicionais, a saber, a condição de mãe que vem, prioritariamente, à condição de mulher, e de amante.

A produção-criação deste sincrético tipo de amor de que fala Morin (1992, p. 38) também se encontra presente na composição das personagens - Helena: todas as três protagonistas são, ao mesmo tempo, essencialmente femininas e ao mesmo tempo sedutoras, embora não tão jovens, e seus romances e affairs muito têm do amor sincrético que envolve o amor espiritual e o amor carnal.

Os amores vividos por tais personagens sempre levam em conta os triângulos amorosos e o sincretismo entre amor Eros e psique, os quais podem ser observados na composição de tais personagens: destacam-se, neste caso, as cenas da protagonista Helena da novela Laços de Família com o seu primeiro par amoroso - $E d u$ - nos quais as cenas de beijos entre uma mulher de aproximadamente cinquenta anos e um jovem de, aproximadamente, vinte cinco, além de conterem uma forte erotização no rosto e no beijo, conjuga, com sucesso, a personagem em um tipo de nova representação: a mulher honesta, mãe, profissional e a amante, sensual, erótica e atraente.

Coincide, portanto, com o que Morin (1969, p. 141) descreve sobre a representação da mulher, que passa a ser, na indústria cultural, uma mistura, espécie de sincretismo, o que Morin, vai chamar de fusão ente virgem e vamp. Sendo que em Morin (1969, p.145) os heróis também trazem em si a totalidade sintética do Eros unido à sua psique, enquanto decaem as virgens e as vamps, os cavaleiros galantes e os vis sedutores.

Neste sentido, os amores e os envolvimentos das personagens se assemelham ao que Morin (1969) descreve, e contribuem para a representação deste novo tipo de mulher-simulacro: aquela que consegue conjugar os valores socialmente aceitos da mulher moderna, tanto como mãe, amante, e os valores tradicionais. O referido panteísmo ilimitado na conjugação e na representação dessas personagens, e que se estende à formação de certos arquétipos sociais, com a produção/criação deste homem médio, se estende na composição deste amor na cultura de massas que é, ao mesmo tempo, profundamente mitológico.

Além de escamotear o incesto, a sexualidade e a morte, na representação e perpetuação de lugares comuns, o amor contribui para a formação destes padrões de comportamentos de atitudes e topoi, e especialmente, no caso analisado, na composição de um padrão de comportamento para as personagens femininas. Sem deixar de haver conflito, os amores das personagens-Helena são sempre regrados de paixão sensualidade, e é claro, vividos sempre de forma responsável e consciente, condições posteriores à condição de mulher mãe. Em tudo isso, tem-se que a composição de personagens femininas protagonistas de Manoel Carlos, 
especialmente as personagens Helena, não são produzidas de forma aleatória, exterior à lógica da indústria cultura e da cultura de massas.

Em entrevista concedida à Revista Cláudia, intitulada: $O$ tradutor da alma feminina, Manoel Carlos relata sobre a produção/ criação de suas personagens: São corajosas e ao mesmo tempo inseguras. Sinceras e dissimuladas, sensuais com uma dose de recato. São felizes, mas sempre querem mais. (CLAUDIA, O tradutor da alma feminina, 2005, p.24).

É o panteísmo comportamental gerado pela cultura de massas, que leva a construir representações que consideram os valores do velho e do novo, da tradição e da modernidade. Este panteísmo comportamental gerado pela cultura de massas cria padrões e representações especulares para a realidade e que por sua vez modificam a realidade com a propagação de valores, atitudes e comportamentos universais. Em introdução à entrevista, a revista declara sobre o autor:

Autor de algumas novelas de maior sucesso da TV, como Laços de Família e Mulheres Apaixonadas, Manoel Carlos constrói heroínas de carne e osso, profundamente verdadeiras. Tanto que toda mulher se identifica com as suas personagens. (...) (REVISTA CLAUDIA, 2005, p. 24)

E ainda, ao se referir ao autor como alguém que conhece a alma feminina, e ao indagar a respeito da composição das personagens, o mesmo declara que para compor as suas personagens ele se alimenta do cotidiano e de fragmentos de identidades femininas: "Converso com amigas, observo as mulheres na rua - muitas me param para contar histórias. Vou ao teatro, viajo, leio e bebo nas revistas femininas (...)" (REVISTA CLAUDIA 2005, p. 23).

Neste sentido, para criar personagens o autor declara se alimentar de fragmentos de identidades, portanto, da coletividade. Ele, então, partiria do cotidiano, a fim de criar representações, modelos, atitudes e comportamentos, pensamentos e lugares comuns para as suas personagens. Em contrapartida, em outra fase da entrevista o mesmo autor declara: não sou pretensioso, mas acho que ajudei algumas mulheres a abrir os olhos e a tomar consciência do papel que exercem em casa (REVISTA CLAUDIA 2005, p. 26).

Ou seja, ao mesmo tempo em que os perfis das protagonistas são produzidos a partir da realidade, a partir de fragmentos identitários femininos, a ficção acaba por criar representações no imaginário popular, sobre os lugares, papéis sociais e os comportamentos femininos. Dessa maneira, a cultura em seu processo especular exerce um importante fator de controle e de construção de ideologias, a partir dessas representações e de repetição de padrões como é o caso da construção das personagens Helena. Portanto, o simulacro midiático, entendido como a duplicação formal da experiência e enquanto fabricação do real possui essa convergência multimidial de transformar as imagens e as representações em realidade para a recepção. O real passa a ser produzido, ou fabricado nas telas, já que as representações criadas nesse processo especular refratam a realidade antes de refleti-la em um processo especular. 
$\mathrm{Na}$ esteira do processo de perpetuação de valores, incidência do tema Amor, consagração entre o sagrado e profano, eros e psique, a construção de representações e de pensamentos comuns, temos a seguinte declaração:

Cláudia. Suas protagonistas estão modernizadas, mas o motor das tramas são os velhos sentimentos como o ciúme e a inveja?

Manoel Carlos. Elas não são só o motor da novela, mas da vida. No fundo no fundo, tudo é uma questão de amor. Por amor pode-se fazer tudo ou quase tudo. O ciúme dá tempero: não acredito na relação sem uma pitada de desconfiança. (,„) Já a inveja é sempre negativa, só prejudica as mulheres. (...) Em Por Amor (1977), Helena troca, escondido, o filho vivo pelo bebê morto da própria filha, a Maria Eduarda. Nas novelas todas mentem, enganam, escondem dos filhos a identidade do pai, não revelam que eles têm irmãos gêmeos, mesmo assim são fascinantes. (REVISTA CLAUDIA 2005. p. 27.)

Portanto tem-se a declaração de que se tratam de "personagens de carne e osso", com as quais o espectador pode se identificar. Além disso, a repetição da fórmula e a incidência de sentimentos e atitudes como ciúme, inveja, amor, mentiras, elementos que se tornam imprescindíveis para que estas personagens se tornem, elas mesmas, elementos de projeçãoidentificação, ao dizer que são fascinantes, e que tais comportamentos são essenciais à vida.

É a constituição de arquétipos que se beneficia do processo de produção na indústria cultural e, especialmente no Brasil, na indústria cultural das telenovelas. Sendo assim, os elementos para a criação de projeção-identificação ficam mais contundentes a partir desta dialética entre ficção e realidade entre produção /criação, entre representação e modelo.

Da declaração do autor, e da análise da formação das personagens tem-se analisado que a preocupação em formar personagens que sejam universais contribui para a manutenção de certas representações sociais, no que tange a formação de atitudes, instauração de modelos no imaginário, conjunto de atitudes e valores. Esses aspectos são perpetuados como comuns a todas as mulheres: amar, sentir ciúmes, colocar a condição de mãe, e em nome desse amor materno ser capaz de mentir e enganar.

No caso das personagens analisadas, em uma História de Amor, a personagem Helena mente sobre a verdadeira origem da filha que, na verdade, era filha adotiva. Em Por Amor, Helena, mente e obriga a outros a mentirem sobre o bebê morto na maternidade, quando resolve doar o filho vivo à sua filha Eduarda. Em Laços de Família, por sua vez, a personagem Helena mente sobre a verdadeira identidade do pai de sua filha Camila.

No entanto, as mentiras, como o próprio autor declara, as tornam fascinantes, porque na indústria cultural a grande motriz temática para que se gerem conflitos e os superem: esta supervalorização do amor tão presente na indústria cultural faz com que se interpretem os atos segundo a lógica do mesmo: por amor se mata, rouba-se, engana-se, e isso não deixa de ser perdoado se se compreende esses atos dentro da força temática maior que rege a cultura de massa, e a sociedade do espetáculo: o amor, tema universal. 
A repetição da fórmula, a incidência de perfis sociais idêntico em telenovelas distintas e de grande repercussão nacional faz com que o imaginário popular seja afetado pelas representações que tais produções de massa acabam por produzir. Tanto que a revista Cláudia denomina o autor Manoel Carlos, como O Tradutor da Alma Feminina. Ao criar personagens que supostamente seriam reflexos de mulheres reais, ele estaria produzindo identidades fixas (estereótipos) e afetando o imaginário popular, em relação aos comportamentos aceitáveis à mulher padronizada, ao tipo de mulher média ${ }^{11}$ produzida e fabricada em suas ficções.

As representações e as identidades passam a ser determinadas pelo real fabricado em uma dialética constante com a ficção. Com efeito, e no caso das personagens-Helena, as representações baseadas em arquétipos reforçam o senso comum, e são efetuadas no processo que corresponde à padronização da Heroína. Uma heroína moderna que conjuga o velho e o novo, ao possibilitar a passagem entre a tradição e à modernidade, entre o sagrado e o profano. Ao conjugar, também, atitudes que refletem valores que confrontam valores antigos, como por exemplo: a troca de bebês em Por amor; ao esconder a verdadeira procedência materna da filha em Uma história do Amor, e ao se deitar novamente com o primo, pai de sua filha mais nova só para ter a chance de oferecer a cura a ela- em Laços de Família, as personagens oferecem elementos dramatúrgicos típicos da tragédia grega ao público espectador: esse gênero que através da visada discursiva (cf. CHARAUDEAU 2004) de fazer-crer, patemiza a audiência, despertando ódio e compaixão.

As Heroínas-Helena de Manoel Carlos são, com efeito, personagens pós-modernas: capazes de colocar em xeque a tradição e romper com os padrões morais vigentes, ao mesmo tempo em os reafirmam, e se redimem, através de atitudes que revelam valores tradicionais. Dentre esses valores destacam-se a sobreposição da identidade materna, à identidade feminina (enquanto gênero), reafirmam a posição, hierarquicamente superior da identidade materna à feminina. Ao mesmo tempo, coaduna com a força endocêntrica e endógena da doxa que (re)definem os papéis sociais, através do simulacro.

Com efeito, a repetição da fórmula, nas três dramaturgias, talvez esteja dentro mesmo dessa força endocêntrica; construída no/pelo consenso, no centro da doxa. Para este sentido, contribuem a ideia mesmo de simulacro (SUBIRATS, 1989), como imagem que refrata um signo distorcido, (BAKHTIN, 1995) mas que se encontra em constante transitar entre a transgressão, transição e com a ruptura e o mesmo como se a intenção fosse, tão somente, a reprodução de valores e a cristalização deles.

Podemos lembrar, no entanto, que a cultura de massas propõe essa ruptura com a tradição e o mesmo. Se a intenção fosse, tão somente a reprodução de valores e a cristalização deles, consideramos, no entanto, que a teoria da cultura de massas propõe a ruptura com a tradição e opera a transição para a modernidade, a fim de gerar essa relação de projeção- 
identificação (MORIN, 1969) e observadas no nosso objeto. Primeiro pela mímese entre o nome-Helena (Heroína da epopeia grega - Ilíada). Segundo pelas relações trágicas, entre mulheres e filhos, nas tragédias gregas, tais como O Édipo Rei, Medéia, entre outras. Enfim, entre essas personagens e suas identidades, ligadas ao mito e aos seus simulacros por representações que não cessam de repetir e romper.

\title{
CONSIDERAÇÕES FINAIS
}

Ao serem observadas a composição de personagens de um mesmo autor (Manoel Carlos), segundo a lógica da cultura massas e a partir de teorias de representação e de simulacro midiático e cultural, pôde-se observar que análise da hipótese proposta na introdução do trabalho é verificável, quando da análise do objeto no que tange à formulação de lugares comuns, de topoi, arquétipos; padrões sociais e comportamentais nas representações proporcionadas pela cultura de massas brasileira.

A repetição da fórmula, a incidência de perfis sociais idênticos nas personagens em telenovelas distintas e de grande repercussão nacional faz com que o imaginário popular seja afetado pelas representações que estas produções de massa acabam por produzir. Tanto que a revista Cláudia analisada nomina o autor como O Tradutor da Alma Feminina. Ao criar personagens que seriam refrações de mulheres reais, repetindo a fórmula em mais de uma trama, ele estaria produzindo identidades fixas (estereótipos) e simulacros e, dessa forma, afetando o imaginário popular, em relação aos comportamentos aceitáveis à mulher média, (re)produzida e (re)fabricada em suas ficções.

Além disso, as representações e as identidades passam a ser determinadas pelo real fabricado em uma dialética constante entre realidade e ficção. Esse processo de transição entre realidade e ficção, na construção de personagens, e no estabelecimento de representações também pode ser melhor entendido, através da mídia e do próprio autor:

\begin{abstract}
Cláudia: Para criar as Helenas, você se inspira em pessoas reais?
Manoel Carlos - Não pretendo falar de política, mas só as mulheres são capazes de trocar de amor como ela fez. Homem não se separa, tenta manter a matriz e a filial. (...). Vocês evoluíram muito rápido, hoje em dia rompem até por amor a si mesmas. Em Sol de Verão (...) as espectadoras rejeitaram a personagem de Irene Ravache (Rachel), que abandonou o marido, um homem rico e bom, dizendo: "Saio de você para ir para mim", Isso é lindo. (...) A determinação da mulher me comove. (REVISTA CLAUDIA, 2005. p. 27)
\end{abstract}

Ou seja, nas palavras do autor e na observação feita pela revista, pode-se perceber a dificuldade de estabelecimento entre o real fabricado, o empírico e a ficção. Ao dizer: vocês evoluíram muito rápido, ao se referir às mulheres (tanto à entrevistadora, como às leitoras da revista) e ao citar, como exemplo, uma personagem da ficção para argumentar este silogismo, o 
autor utiliza a fala de uma de suas personagem. Com efeito, o trânsito ente real e imaginário, e as barreiras entre ambos, ficam mais tênues.

E é nesse constante transitar que os lugares comuns são acionados, os padrões e os processos identitários são (re)criados. O estabelecimento de padrões e normas de comportamentos, a partir da cultura de massas, afeta o imaginário e contribui para a manutenção, perpetuação, ou transformação de certas ideologias, no que concerne ao conjunto de valores, crenças, normas.

Neste sentido, a cultura de massas e a indústria cultural estão nesse entrelugar de estabelecimento e de produção de padrões para a realidade, contribuindo para instaurar, renovar ou manter certos estereótipos. Dessa forma, entende-se por representações sociais e discursivas um movimento abstrato que propicia a reprodução de pensamentos, modelos, comportamentos e gera, por sua vez, comportamentos e atitudes que vão de encontro ao sistema de normas e valores que regem a cultura, especialmente, e no caso do trabalho proposto, a cultura de massas brasileira.

\section{REFERÊNCIAS}

BAKHTIN, Mikhail. Marxismo e filosofia da linguagem. Trad. Michel Lahud e Yara F. Vieira. São Paulo. Hucitec.1981.

BARBERO, Jesus Martin. Indústria cultural: capitalismo e legitimação. In: BARBERO, Jesus Martin. Dos meios às mediações - Comunicação, cultura e hegemonia. Rio de Janeiro: Editora da UFRJ, 1997.

CHARAUDEAU, Patrick. Visadas discursivas, gêneros situacionais e construção textual. (In). MACHADO, Ida Lúcia e MELLO, Renato de. Gêneros e reflexões em análise do discurso. Belo Horizonte - Nad/Fale/ UFMG, 2004.

HALL, Stuart. A identidade cultural na pós-modernidade. Trad. Tomaz Tadeu Silva, Garacira Lopes Louro. Rio de Janeiro: DP\& A. 1998.

JODELET, Denise. As representações Sociais: um domínio em expansão: (In):As representações sociais. Rio de Janeiro: Eduerj. 2001.

MORIN, Edgar. Cultura de massa no século XX. Rio de Janeiro: Forense, 1969 pp. 37-80.

MORIN, Edgar. A cultura de massas do século XX. (In). MORIN, Edgar. O amor. Rio de Janeiro: Forense,1969.pp.137-145.

ORTIZ, Renato. BORELLI, Silvia, Helena Simões. ORTIZ, José Márcio. Telenovela: História e Produção. São Paulo: Brasiliense, 1989.

REVISTA CLAUDIA, In: Entrevista: O tradutor da alma feminina. Abril: 2005, pp.24-27.

SUBIRATS, Eduardo. A cultura como espetáculo. ( In):SUBIRATS, Eduardo.A cultura como simulacro. São Paulo: Nobel, 1989. 


\section{Notas:}

\footnotetext{
${ }^{1}$ Doutoranda em Estudos Linguísticos pelo Programa de Pós-Graduação em Estudos Linguísticos da Faculdade de Letras da UFMG-POSLIN/FALE/UFMG. E-mail: cristiamiranda@gmail.com.

${ }^{2}$ Ficção dramatúrgica.

${ }^{3}$ Entrevista concedida à Revista Cláudia, editora abril, $\mathrm{O}$ tradutor da alma feminina

${ }^{4}$ Revista Cláudia ,intitulada $\mathrm{O}$ tradutor da alma feminina.

${ }^{5}$ Enredo do gênero Novela.

${ }^{6}$ Sobre isto, ler: O mito da Caverna, Platão.

${ }^{7}$ Categoria psicanalítica freudiana para descrever as instâncias do ser de outrem.

${ }^{8}$ Categoria psicanalítica para a descrição da instância do ser: $i d$, ego, superego.

${ }^{9}$ Termo cunhado por Morin (1969)

${ }^{10}$ Conforme propõe Morin (1962), e fazemos a transposição para o conceito de Homem médio, ao se referir ao indivíduo frente à cultura de massas e à pós-modernidade.

${ }^{11}$ Transposição categórica, feita pela autora, acerca do Homem Médio descrito por Morin (1969).
} 